\title{
NEUROTROPHINS CAN ENHANCE SPIRAL GANGLION CELL SURVIVAL AFTER INNER HAIR CELL LOSS
}

\author{
JOSEF M. MILLER,* DAVID H. CHI, LEONARD J. O'KEEFFE, PAUL KRUSZKA, \\ YEHOASH RAPHAEL and RICHARD A. ALTSCHULER \\ Kresge Hearing Research Institute, University of Michigan, Ann Arbor, MI 48109-0506, U.S.A.
}

\begin{abstract}
Following destruction of sensory cells of the organ of Corti, spiral ganglion cells (SGC) in the guinea pig degenerate. Chronic electrical stimulation via cochlear prostheses can enhance their survival, with the effect blocked by stopping the electrically elicited action potentials with tetrodotoxin. Blocking action potentials in the normal hearing ear with tetrodotoxin, however, does not cause degeneration. This suggests that in the pathological ear VIII $\mathrm{N}$ activity acts as a survival factor, while in the normal ear there are other survival factors that maintain SGCs. We examined neurotrophins, as survival factors in the deafened ear. Two weeks of treatment with BDNF (brain derived neurotrophic factor) administered chronically via a mini-osmotic pump into scala tympani at $50 \mathrm{ng} / \mathrm{ml}$, provided a statistically significant enhanced SGC survival over untreated deafened ears or deafened ears treated with artificial perilymph. Neurotrophin 3 provided some enhanced survival, but this was not statistically significant over untreated deafened ears. These observations suggest there are survival factors in the inner ear, including those coupled to direct activation of the auditory nerve fibers, that may serve to maintain the auditory nerve. These factors may be applied following deafness to maintain and enhance neural populations and to increase benefits to the profoundly deaf receiving cochlear implants. (C) 1997 ISDN
\end{abstract}

Key words: neurotrophins; inner ear; auditory neurons; BDNF; NT-3; ototoxicity; spiral ganglion cells; guinea pig.

During the last 10 years the development of techniques in molecular biology have had a major impact on research of the inner ear. New molecular strategies have provided insight into the basic subcellular mechanisms that underlie inner ear tissue functions and have provided new methods of intervention that allow us to address important basic and clinical issues of inner ear function, such as tissue protection under stress, maintenance following trauma, and the modulation of repair processes associated with pathology. Methods which up- and down-regulate the production of proteins that affect function (e.g. stress proteins) have been important in this work to date and hold even greater promise for the future. The use of exogenously applied agents (drugs, chemicals, proteins) to influence tissue functions has also received increased attention ${ }^{40,47}$ as we develop improved delivery systems and better define the molecular targets and mechanisms underlying the influence of agents on sensorineural tissues. Because of their powerful influence to control nerve growth, neurotrophins are a class of agents receiving enthusiastic attention in the neurosciences. With the development of new locally restricted drug delivery systems, investigators are beginning to assess the effectiveness of neurotrophins in modifying inner ear function and tissue response to stress. ${ }^{8,21.31 .39,43}$

Our group is investigating changes that occur following deafness and the development of interventions to prevent degenerative and down-regulatory changes that may occur. We have been particularly interested in the auditory nerve changes that occur after inner hair cell loss, because of the increasingly clear dependency of benefits of the cochlear prosthesis on the quality and quantity of the auditory nerve population. Evidence exists that the perceptual benefits of the cochlear prosthesis depend significantly on the density of surviving auditory nerve fibers. ${ }^{13,19,33,34}$ Hair cell

*To whom all correspondence should be addressed.

Abbreviations: BDNF, brain derived neurotrophic factor; NT-3, neurotrophin 3; trk, tyrosine kinase; trkB, BDNF receptor; trkC, NT-3 receptor; kanamycin, s.c, $400 \mathrm{mg} / \mathrm{kg}$; ethacrynic a. c. i. d., i. v. $40 \mathrm{mg} / \mathrm{kg}$; SGC, spiral ganglion cells; TTX, tetrodotoxin; ST-3, chemical survival factor; dSGCi, implanted stimulated ear; dSGCni, nonimplanted ear; $5 \mathrm{~d} /$ week, daily; CNTF, ciliary neurotrophic factor; NGF, nerve growth factor; GDNF, glial derived neurotrophic factor; GAP-43, growth cone associated protein 43 . 
replacement, if it can in the future be induced by regeneration, would depend on surviving auditory nerves for reconnection.

We have examined the effects of deafness on the peripheral and central auditory systems. Our studies have been performed on rats and guinea pigs deafened either with topical neomycin, which permits a unilateral deafening, or systemic kanamycin and ethacrynic acid, which provides a bilateral effect. ${ }^{17,49,51}$ Both procedures yield a profound loss of inner and outer hair cells throughout the cochlea, except occasionally for a few scattered inner hair cells at the apex. The hair cell injury and loss is then followed by a retraction of the peripheral processes of the auditory nerve $e^{42}$ and later by a gradual loss of auditory nerve cell bodies (spiral ganglion cells, SGC). Studies by Webster and Webster ${ }^{48,49}$ and our group ${ }^{17,54}$ in the guinea pig show that the population of SGC is reduced by about $50 \%$ at 9 weeks after inner hair cell loss, and the SGC population continues to diminish to ca $25 \%$ at 16 weeks, and may stabilize at $8-12 \%$ by 2 years. The pathological changes in SGC are associated with a decrease in the slope of the amplitude input/output function of the electrically evoked middle latency response and the auditory brainstem response. The correlation between the change in slope and the decrease in density of SGC is $c a r=0.8 .{ }^{17}$

In the auditory periphery, with ototoxic induced deafness at the level employed in these studies, there is a significant change in inner ear tissues, including loss of inner hair cells and changes in supporting cells and efferent terminals. Each of these structures may contribute chemical survival factors for SGC. The level of drug treatment used in these studies results in loss of all hair cells, except occasionally a few scattered survivors at the apex. The scar formation is comparable to what has been previously described for this ototoxic agent ${ }^{37}$ and other types of insults. ${ }^{2.7}$ Hair cell loss and scar formation proceeds at a more advanced pace in the basal turns than apical turns. The first stage of scar formation which we have termed "type I" ${ }^{37}$ occurs as early as $9 \mathrm{hr}$ after drug administration and consists of replacement of first row outer hair cells through expansion of outer pillar cells while second and third row outer hair cells are replaced by first and second row Deiters cells. ${ }^{37}$ The next phase of scar formation (type II) involves the loss of inner hair cells, along with pillar cells. This phase is marked by the loss of the tunnel of Corti and occurs within days after drug administration. Often type II scar formation is seen in basat turns while type I is still occurring in the apical turns. The third phase occurs several weeks after drug administration, and involves replacement and flattening of the remaining supporting cells. Again, the basal turns may be in this third phase while type II scars are still observed in the more apical turns. Type II and type III scars, with the loss of inner hair cells and changes in supporting cell structure, are correlated with loss of peripheral processes and eventual loss of associated SGCs. We view this SGC loss as secondary to the loss of inner hair cells and supporting cell changes, rather than a direct effect of the ototoxic drugs, for reasons similar to those expressed by Lawner et al. ${ }^{22}$ for noise induced degeneration, that is, because of the delay in first signs of nerve cell loss, 2 weeks following treatment.

We believe that the loss of hair cells and changes in supporting cells and efferents could result in changes in the local delivery of one or more survival factors important to the continued maintenance of SGC. Neurotrophins are an important family of chemical survival factors which have received significant attention both in the auditory system and elsewhere over the last decade. Recent investigations have defined the presence of neurotrophic factors in the inner ear, ${ }^{52,53}$ and the presence of their receptors on cochlear cells. ${ }^{53}$ Studies have also begun to define the effects of providing neurotrophic factors on ear tissues, ${ }^{8,14,26,27,39,41,43,46,55}$ and to determine the changes in the inner ear that occur in transgenic mice who do not express these survival factors. ${ }^{9-12}$ These studies have provided a compelling picture of the importance of these factors for the inner ear, particularly during development. Across these investigations, to date, the bulk of the evidence supports the role for brain derived neurotrophic factor (BDNF) and neurotrophin 3 (NT-3) in determining both the quantitative innervation and the innervation pattern across the sensory receptors of the inner ear. Tyrosine kinase (Trk) receptors appropriate for these factors are present in the tissue,,$^{52,53}$ and the factors have been identified at various stages of development and maturation. ${ }^{35,36,38}$ Effects on survival and neurite outgrowth have been reported ${ }^{8,20.21,29,44,46}$ and in mice knockouts, in which the gene necessary to express the neurotrophic factor is missing or the appropriate receptor cannot be expressed, remarkable changes in inner ear structure are reported..$^{9-12}$ Particularly impressive is the recent evidence, based on receptor knockout, that the BDNF and NT-3 differentially effect the development of inner ear innervation both qualitatively in the innervation pattern and quantitatively 
in the relative number of fibers, with BDNF particularly important for the vestibular portion of the inner ear and NT-3 the cochlea. Thus, the loss of trkB (BDNF receptor) eliminates canal innervation and reduces it in the vestibule and middle and apical turns of the cochlea, while loss of trkC (NT3) only reduces middle and apical turn cochlear innervation. Loss of both eliminates all inner ear innervation. BDNF appears to be particularly apt for vestibular end organs, while NT-3 is particularly effective in the cochlea. ${ }^{12}$ Of course these and many other studies on these factors in the ear were performed on developmental material and hence must be generalized with care to the mature animal or mature pathological preparation. We examined the influence of chronic infusions of the neurotrophins BDNF and NT-3 on SGC survival after inner hair cell toxicity using the miniosmotic pump and chronic microcannulation method developed in our laboratory. ${ }^{4}$

\section{EXPERIMENTAL PROCEDURES}

Neurotrophins were chronically applied (BDNF, source: Genentech; NT-3, source: Austral) into scala tympani of the guinea pig (200-350 g, Murphy) cochlea via mini-osmotic pumps. Five subjects received BDNF, five received NT-3, and a control group of three subjects received artificial perilymph (AP).

On day 0 , experimental groups were systemically treated with administration of kanamycin (subcutaneously, $400 \mathrm{mg} / \mathrm{kg}$ ) and, two hours later, ethacrynic acid (intravenously, $40 \mathrm{mg} / \mathrm{kg}$ ). As originally demonstrated ${ }^{49,51}$ and subsequently supported in our laboratory ${ }^{17,37}$ this drug dose results in bilateral elimination of all cochlear hair cells except occasionally for a few remaining inner hair cells at the apex, and extensive loss of supporting structures, particularly through the basal half of the cochlea. On day 7 , animals were unilaterally implanted with mini-osmotic pumps (see the technique described by Brown et al., ${ }^{4}$ ) with drug primed cannulas, and infusions were initiated and maintained for a period of 14 days, until experimental day 21. Experimental Group 1 animals received human recombinant $50 \mathrm{ng} / \mathrm{ml}$ BDNF, Group 2 animals received $50 \mathrm{ng} / \mathrm{ml} \mathrm{NT}-3$ and Group 3 animals received the AP. Chronically implanted osmotic pumps released $0.5 \mu \mathrm{l} / \mathrm{hr}$. On day 14 of the experiment, the osmotic pump was changed to ensure viable test material. On experimental day 21 , animals were heavily anesthetized and perfused with $4 \% p$-formaldehyde, followed by local perfusion, decalcification in 3\% ethylenediaminetetra-acetic acid and embedded in plastic (EMbed 812).

Cochleae were then sectioned at $6 \mu \mathrm{m}$ in a mid-modiolar plane, with every fourth section kept. Mid-modiolar sections contain seven profiles of the cochlear spiral, and with our plane of sectioning these are approximately centered around regions 6, 9, 10.5, 12, 14, 16 and $17.5 \mathrm{~mm}$ along the cochlear spiral, respectively. The five most mid-modiolar sections were chosen (each separated by $18 \mu \mathrm{m}$, defining a reference space of $120 \mu \mathrm{m}$ for each of the seven profiles). The number of SGC was determined for each cross-cut profile of the Rosenthal's canal on each of the six sections for each animal, using the Metamorph ${ }^{\mathbb{R}}$ image acquisition and analysis system. The outline of each Rostenthal's canal profile was also traced with the Metamorph ${ }^{\mathbb{B}}$ system to generate an area which was then used to produce a SGC density within that profile. The SGC density means were calculated for each profile, and statistical analyses were performed with the SigmaStat v 2.0 computer program. SGC density was compared between each of the three groups of this study (i.e. BDNF, NT-3, and AP treated) and with SGC density observed in a group of six normal ears of comparable weight subjects (i.e. untreated and uncannulated). The fractionator method ${ }^{6}$ was also used to compare total SGC numbers within the reference area in lower basal turn, between BDNF, NT-3, AP treated and nontreated cochleae.

In a second set of five subjects, a similar deafening and cannulation procedure was performed, but the subjects received chronic infusion of a cocktail of neurotrophic factors, including both NT3 and BDNF at $50 \mathrm{ng} / \mathrm{ml}$, plus ciliary neurotrophic factor (CNTF) at $50 \mathrm{ng} / \mathrm{ml}$, and glial derived neurotrophic factor (GDNF) at $10 \mathrm{ng} / \mathrm{ml}$. In these subjects cannulation and drug treatment was initiated on day 4 following deafening. These subjects were assessed on experimental day 32, after 28 days of neurotrophin treatment. The temporal bones, including both cannulated ears and the contralateral control ear of each subject, were fixed in a fashion similar to the first subject set, but processed for immunocytochemistry in cryostat (mid-modiolar) or surface preparations, using 
antibodies to neurofilaments (Boehringer-Mannheim) or growth cone associated protein 43 (GAP43) (L. Docas), and studied under light and fluorescence microscopy for detection of peripheral process growth.

\section{RESULTS}

\section{Organ of Corti}

Complete loss of inner and outer hair cells occurred in all animals of all three experimental groups (BDNF, NT-3 and AP). In all groups there was some variation between animals in the phase/extent of scar formation. In the AP control animals there was excellent symmetry between sides in the extent and phase of scar formation, which is typical of what we have previously observed with systemic kanamycin plus ethacrynic acid deafening. In many animals treated with BDNF or NT3, however, there was not the usual symmetry between sides, with the extent of scar formation apparently delayed on the treated side. This was most noticeable in neurotrophin treated animals in which scar formation on the untreated side demonstrated greater progression, with loss of the tunnel of Corti. This asymmetry in scar formation was greatest in BDNF treated subjects. In the first and second turns of these animals, Deiters cells, pillar cells and the tunnel of Corti were still present in the treated side (Fig. 1A and B) while in the contralateral, untreated cochlea there was full or partial loss of Deiters cells, pillar cells and the tunnel of Corti, with flattening of the remaining epithelium (Fig. 1C and D). Thus, chronic application of BDNF (and to a lesser extent NT-3) after hair cell loss, appears to prevent or delay cell death and loss of pillar cells and other supporting cell elements whose turnover and replacement is part of normal scar formation.

Perilymphatic infusion of BDNF, following hair cell loss, also resulted in a significant increase in the mean SGC density in the basal (first and second) turns of the treated cochlear spiral, compared to the contralateral untreated side as well as the cochleae receiving AP (Fig. 2). The mean SGC density for an area of $10000 \mu \mathrm{m}^{2}$ in the first (basal) turn of cochlea receiving AP was 12.3 $($ S.E.M. $=1.1$ ) cells while treatment with BDNF increased surviving mean SGC density to 18.1 $($ S.E.M. $=1.1)$. The BDNF treated group demonstrated a statistically significant difference from the ototoxically deafened group treated with AP $(P<0.01$, Student $t$-test). Moreover, there was no significant difference in the density of SGC in the BDNF group compared to SGC density observed in the group of normal ears, with no degeneration. This significant difference was also seen when we compared total SGC numbers in the lower basal turn reference space, between BDNF treated cochlea compared to nontreated cochleae or cochleae that received AP (Fig. 2B).

In Fig. 3, the percentage (enhancement) of SGC survival in the BDNF group after ototoxicity, over and above that seen in the contralateral noncannulated ear, is shown for three different cochlear sites. The three sites studied include one at the basal turn immediately adjacent to the cochlear cannulation, a site on the opposite side of the cochlea in turn 1, and a second site in turn 2, immediately above the cannulation site in turn 1 . The greatest enhancement of survival of SGC was observed adjacent to the implant. The enhanced survival of SGC was quite reduced at the cochlear site opposite to the implant. The turn 2 site, immediately above cannulation, showed an intermediate value for SGC survival density and enhancement. Because of the variability, these differences were not significant. We note that the similarity in SGC density in the BDNF group that was cannulated as well as deafened indicates that the chronic cannulation has little or no damaging effect on SGC. This is supported by observations of similar SGC density in normal and AP treated groups.

Treatment with NT-3 begun 7 days after ototoxicity and continued for 2 weeks increased surviving mean SGC density to 14.9 (S.E.M. $=0.96)$ cells $/ 10000 \mu \mathrm{m}^{2}$, compared to a mean SGC density of 12.3 cells $/ 10000 \mu \mathrm{m}^{2}($ S.E.M. $=1.1$ ) in cochlea receiving AP. This difference, however, was not significant. The difference between the SGC survival density between BDNF and NT-3 treatment conditions was significant at $P<0.05$ (Student's $t$-test). BDNF was therefore more effective than NT-3 in enhancement of SGC survival. There was also less apparent difference in the rate of scar information in these NT-3 animals.

\section{Peripheral process growth}

In the experimental group used for peripheral process assessment, receiving chronic treatment after hair cell loss with a "cocktail" of neurotrophins, individual neurofilament immunostained 


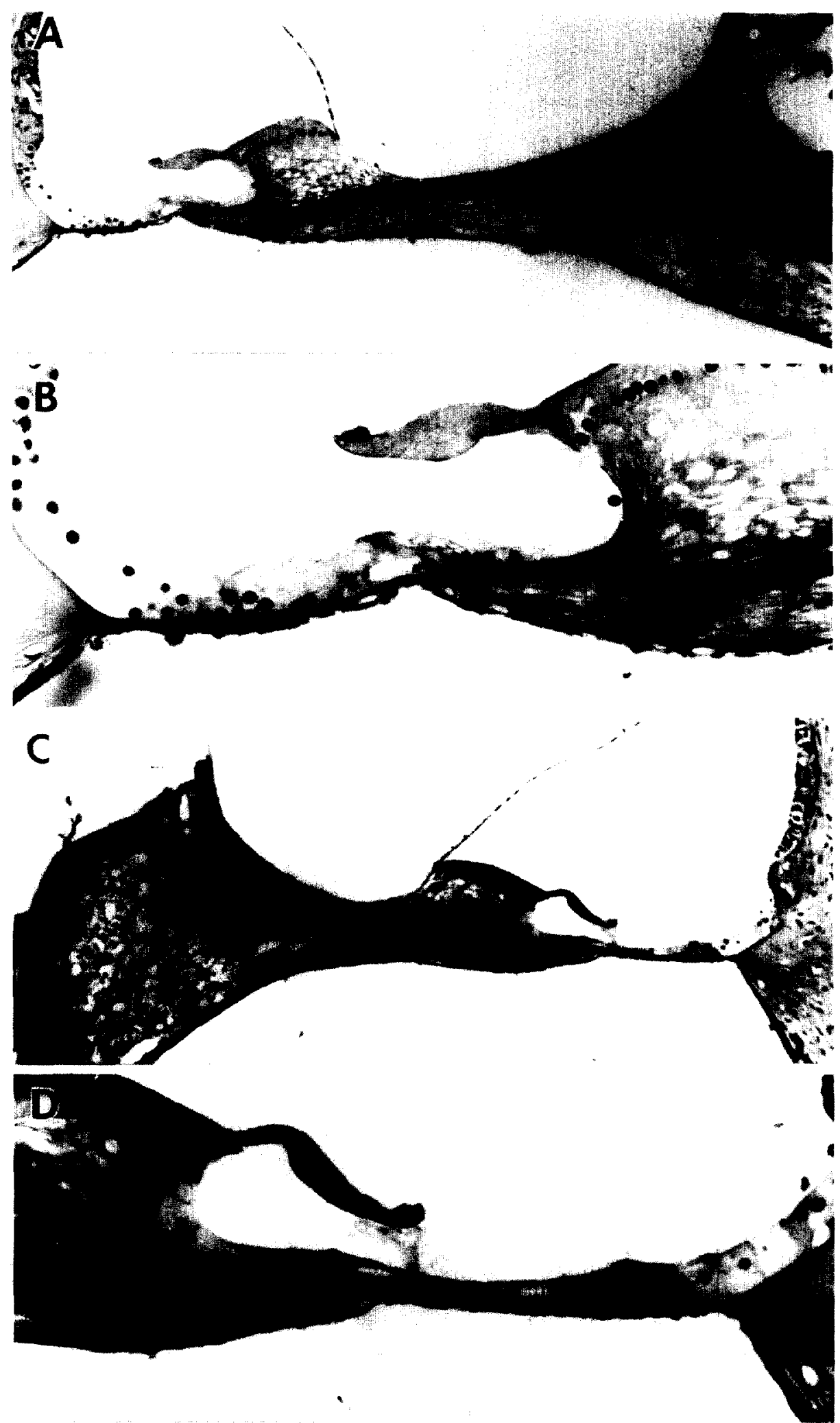

Fig. 1. (A) Photomicrograph of a section through the lower basal turn of a cochlea treated with BDNF showing the organ of Corti and spiral ganglion cells in Rosenthal's canal. (B) A higher magnification micrograph of the same section, showing the organ of Corti, with pillar cells and the tunnel of Corti still present, while inner and outer hair cells are missing. (C) Photomicrograph of a section through the lower basal turn of the contralateral, untreated cochlea, showing the organ of Corti and spiral ganglion cells in Rosenthal's canal. (D) A higher magnification micrograph of the same section, showing the organ of Corti, with missing hair cells and with missing Deiters cells, pillar cells and tunnel of Corti. A greater survival of SGC and a slower progression of scar formation with less loss of supporting cell structure is seen in the BDNF treated cochlea (A and B) than untreated cochlea (C and D). 

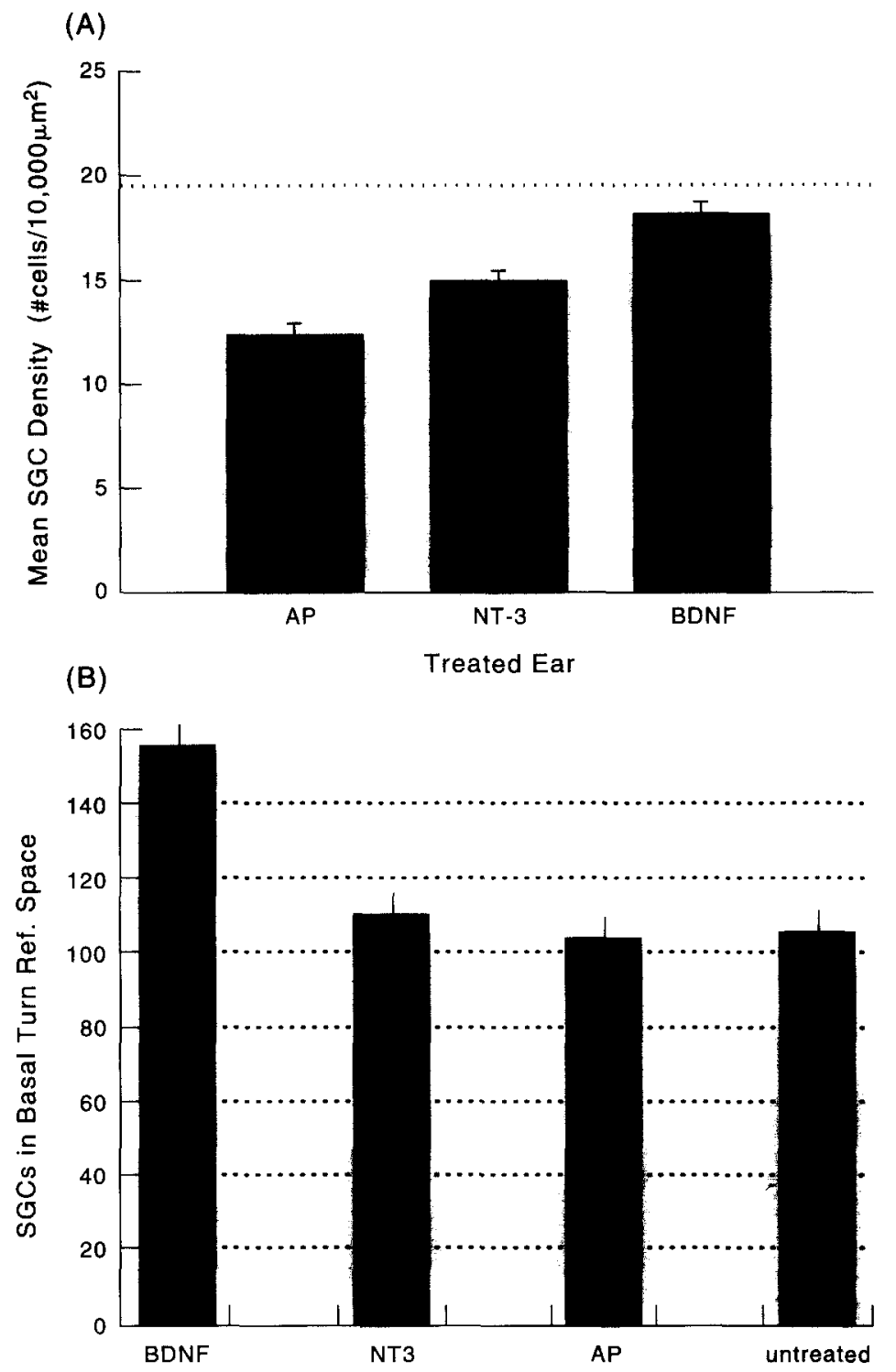

Fig. 2. (A) The mean SGC density (No. cells $/ 10000 \mu \mathrm{m}^{2}$ ) and S.E.M. after treatment with AP, NT-3 or BDNF. Perilymphatic infusions were begun 7 days after ototoxicity and lasted for 14 days. The mean SGC density in the basal turns of cochlea receiving AP was 12.3 (S.E.M.: 1.1); NT-3 was 14.9 (S.E.M.: 0.96); and BDNF was 18.1 (S.E.M.: 1.1). The effect of BDNF compared to AP was significant at $P<0.01$. (B) A comparison of the average number of SGCs in a $120 \mu \mathrm{m}$ long reference (ref.) area (centered $6 \mathrm{~mm}$ along the cochlear spiral in the lower basal turn) between animals whose cochleae were chronically treated after deafening with BDNF, NT-3, AP or nontreated. Error bars represent S.E.M.

fibers could be seen exiting from the habenula perforata. These often curled under the osseous spiral lamina, as is shown in Fig. 4A. Punctate immunostaining for GAP-43, a growth cone marker, could often be seen, usually associated with the growing end of fibers. This can be observed in Fig. 4B, a double exposure of neurofilament staining (appearing reddish-orange) and GAP-43 immunostaining (a puncta marked by an arrow and appearing yellowish orange). Figure $4 \mathrm{C}$ and $\mathrm{D}$ show adjacent cryostat sections, with GAP-43 immunostaining in Fig. 4D associated with the end of neurofilament immunolabeled fibers in Fig. 4C.

\section{DISCUSSION}

These studies indicate that chronic infusion of BDNF enhances SGC survival after inner hair cell loss. Based on our previous results showing that electrical stimulation also enhanced SGC survival 


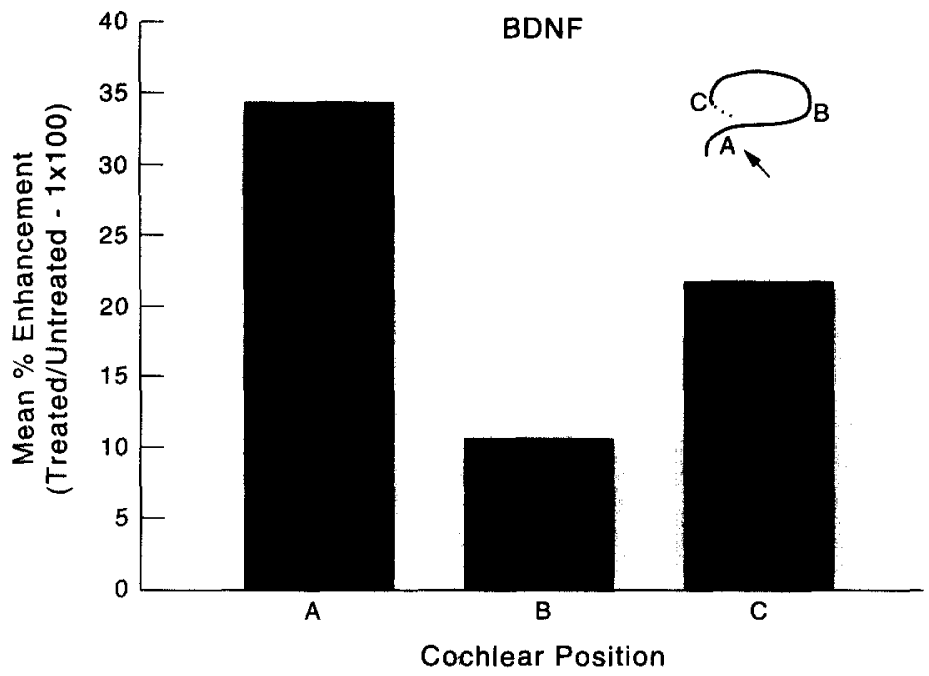

Fig. 3. The mean \% enhancement of SGC survival in the BDNF-treated ear compared to the contralateral untreated ear. (A) The enhancement in survival in turn 1 , site of cannulation is $34.6 \%$. (B) The enhancement in survival in turn 1 , site contralateral to the implant is $10.9 \%$. (C) The enhancement in survival in turn 2 , site immediately above the cannulation site in turn 1 is $22.2 \%$.

after deafness, it seems reasonable to speculate that several survival factors including neurotrophins and neural activity may be involved in SGC maintenance. These data indicate that the application of these factors may be useful in inducing a survival of auditory nerve elements following deafness.

An important finding for understanding mechanisms that underlie cell survival is that electrical stimulation of the auditory nerve can enhance SGC survival following deafness. ${ }^{16,23-25,28,30}$ We now know $^{30}$ (Fig. 5A) that immediate electrical stimulation enhances SGC survival after deafness, such that following 9 weeks of deafness, as much as $80 \%$ of the normal density in cells in the region stimulated chronically may be preserved by comparison to a $50 \%$ survival in nonstimulated ears. Stimulation introduced 4 weeks following the onset of deafness (Fig. 5B) can still yield a positive influence on cell survival. Thus, enhanced survival may occur even after degeneration has begun in some of the elements. ${ }^{30}$ Continuous $(24 \mathrm{hr} /$ day) stimulation is equal in effectiveness as intermittent stimulus in enhancing survival (Fig. 5C). Finally, even a minimal level of stimulation ( $\mathrm{ca} 30 \mathrm{~min}$, once a week), initiated 1 week following deafness (Fig. 5D), can significantly preserve SGC. ${ }^{30}$ Thus, it appears that the survival factors provided by electrical stimulation are adequate to significantly maintain SGC survival (up to $80 \%$ ) with intermittent stimulation. Moreover, enhancement of SGC survival (up to $60 \%$ ) is provided with stimulation as infrequent as once per week.

It is reasonable to speculate that SGC may die following deafness because of the loss of excitation (an analagous model to the muscle "use it or lose it," in which a disuse atrophy occurs). To examine the role of activity in maintaining SGC, we tested the hypothesis that propagated action potentials in the SGC evoked by chronic stimulation in the deafened ear were responsible for their enhanced survival. Using the recently developed technique of mini-osmotic pumps and chronic microcannulation of scala tympani ${ }^{4}$ deafened animals unilaterally received chronic stimulation with a cochlear prosthesis and chronic intrascalar perfusion of $25 \mu \mathrm{M}$ tetrodotoxin (TTX). Under these conditions, in which the electrical evoked propagated action potentials are blocked, no enhancement of SGC survival was observed. ${ }^{31}$ This indicates that SGC activity promotes survival of SGC after ototoxicity. In a second experiment, we observed that TTX block (4-8 weeks) of activity in the normal ear does not induce SGC death. During TTX treatment, click evoked ABR thresholds were elevated by $>60 \mathrm{~dB}^{31}$ This indicates that replacement of electrical activity in SGC enhances their survival after deafness; however, removal of activity in the otherwise normal ear, does not induce SGC death. Our explanation for this is based on the hypothesis that activity is just one of several survival factors involved in the maintenance of mature SGC and the presence of any major survival factor is sufficient for maintenance. Thus, providing any major survival factor lost to the deafened ear enhances survival; removing just one will not cause death in the normal ear, where many are 

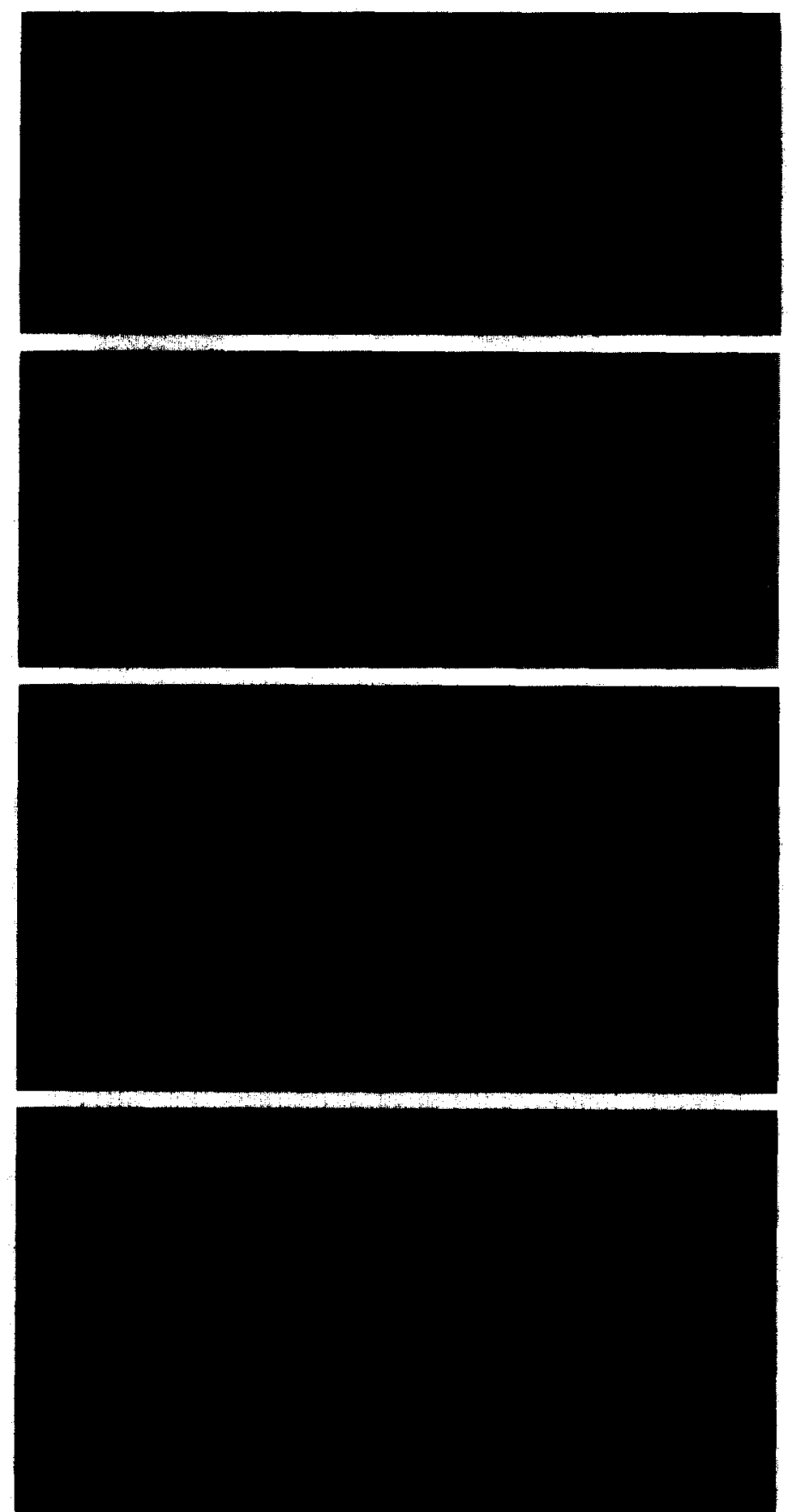

Fig. 4. Photomicrographs of neurofilament (A, B, C) or GAP 43 (D) immunostaining on cryostat sections (A, C, D) or surface preparations (B) of the guinea pig cochlear spiral. (A) Neurofilament immunostaining in a cryostat section of a guinea pig cochlea treated with chronic infusion of a cocktail of neurotrophins (BDNF, NT-3, CNTF and GDNF). A process is seen (arrowhead) which emerges from the osseous spiral lamina and curls under it. (B) Combined neurofilament (Rhodamine-showing orange) and GAP-43 (FITCshowing yellow) immunostained in a double-exposed photomicrograph. A puncta of GAP-43 immunostaining can be seen (arrow) medial to the neurofilament immunostained tunnel and inner spiral bundles. (C and D) Adjacent sections immunostained for neurofilaments (C) and GAP-43 (D). GAP 43 immunostaining [arrow in (D)] can be seen at the end of neurofilament immunostained fibers (C).

present. If this is the case, other survival factors, besides activity, should also enhance SGC survival after deafness.

We have assumed that the trends observed reflect the differences in distribution of available BDNF in the cochlea, with the greatest concentration of BDNF occurring immediately adjacent to 


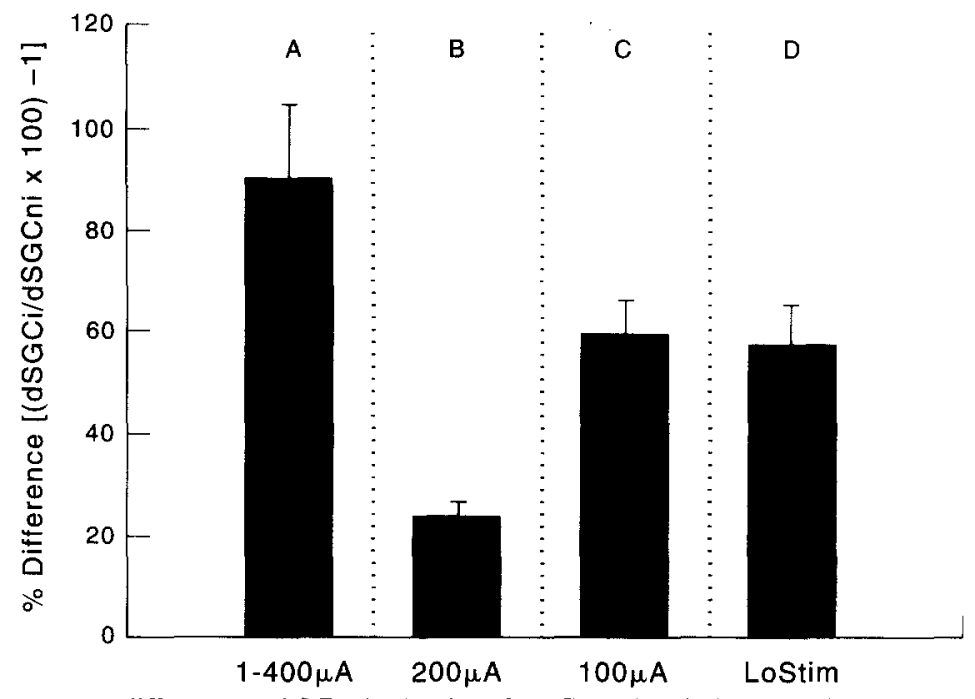

Fig. 5. Mean percent difference and S.D., in density of SGC survival in implanted stimulated ear (dSGCi) vs nonimplanted ear (dSGCni) with different parameters of chronic stimulation. (A) Daily ( $5 \mathrm{~d} /$ week) intermittent stimulation for 9 weeks begun immediately following deafness. The result presented is the mean of four groups of subjects stimulated at $1,2,3$ or $400 \mu \mathrm{A}$. No significant difference was observed among these groups. (B) Daily intermittent stimulation at $200 \mu \mathrm{A}$ for 5 weeks begun 4 weeks (delayed) following inner hair cell loss. (C) Continuous stimulation at $100 \mu \mathrm{A}$ for $1000 \mathrm{hr}$ (42 days) beginning shortly ( 8 days) following ototoxicity. (D) LoStim indicates electrical stimulation (begun 8 days after deafening) only during weekly electrically evoked auditory brain stem response (EABR) input-output recordings (ca $30 \mathrm{~min}$ ). (Modified from Miller and Altschuler. ${ }^{30}$ )

the site of cannulation, with sites further removed demonstrating a reduced concentration of factor and hence reduced cell survival. We speculate that the tendency for enhanced survival in turn 2 reflects the ready access of BDNF to Rosenthal's canal through the habenula perforata and an enhanced concentration of BDNF in the region of SGCs at that turn, immediately above the site of implantation, by comparison to BDNF concentration at the site one half turn removed. Alternatively, it may reflect an enhanced sensitivity of turn 2 to BDNF over some parts of turn 1, for which there is some supporting data from developmental studies.

These data are consistent with a model of the inner ear as illustrated in Model la (Fig. 6A). This model is based upon the assumption that a variety of tissue elements of the normal inner ear may be viewed as providing survival factors that influence the cochlear nerve. Many of the survival factors may directly or indirectly involve neurotrophins. One survival factor reflects the influence of inner hair cells on SGC. This may be provided in a chemical transmitter that depolarizes the cell membrane resulting, on occasion, in depolarization and a propagated action potential (SF2b) in the auditory nerve, but there may as well be a rich variety of other chemical factors provided by the inner hair cell. In the case of the propagated action potential, a survival factor influencing the SGC may be provided through the activity itself or, secondarily, the activity may act in an autocrine manner to release a chemical survival factor (SF3) that in turn influences the survival of SGC. Recent studies' have demonstrated the presence of a BDNF autocrine loop in adult dorsal root ganglion cells. Within the modiolus, Schwann cells may provide influential factors (SF6). Studies have shown that Schwann cells are a source for a variety of factors, including nerve growth factor (NGF), CNTF, and BDNF. ${ }^{5}$ These are in addition to survival factors potentially provided by efferent fibers (SF4) and other supporting elements of the inner ear (SF5). With inner hair cell loss there occurs a rapid degeneration of nonmyelinated peripheral elements of the SGC. Presumably this occurs because of the variety of survival factors eliminated, including those from hair cells, supporting cells, those associated with evoked activity, autocrine factors associated with nerve activity, and eventually the loss of efferent system provided survival factors. As suggested by Model 1c (Fig. 6B) we propose that cochlear implantation and the chronic cannulation of the scala tympani for the delivery of agents provide us the means to replace many of these factors. As discussed, these include electrical activity and a variety of neurotrophic and other survival factors. The technology 
and strategies being developed offer an opportunity to examine the effects of a variety of factors and agents, as well as to study the effects of a combination of agents.

This study indicates that neurotrophins may not only function to induce survival of SGC, but may also induce regrowth of peripheral processes. This protection of SGC following ototoxic induced damage to the organ of Corti is consistent with the recent report by Ernfors et al. ${ }^{8}$ These authors demonstrated a significant enhancement of the survival of the auditory nerve in subjects simultaneously treated with NT-3 $(310 \mathrm{ng} / \mathrm{hr})$ at the time of administration of amikacin, compared with a group receiving amikacin and AP. The appearance of Gap 43 staining and single fibers in neurotrophin treated animals present a compelling picture of the neurotrophin induced neurofilament growth in the mature pathological cochlea. The fiber growth is similar to what was observed by Bohne and Harding ${ }^{3}$ and Lawner et al. ${ }^{22}$ with regrowth after focal lesions of the cochlea. The masses of fibers observed by Staecker et al. ${ }^{43}$ with NT-3 plus BDNF treatment at $1 \mathrm{mg} / \mathrm{ml}$, were not observed, perhaps because of our lower (4log units) concentration of neurotrophins and our shorter period of application.

The literature on BDNF and NT-3 expression, distribution of receptors, and the effect of disrupting these factors and their receptors, would suggest that NT-3 should have a much stronger

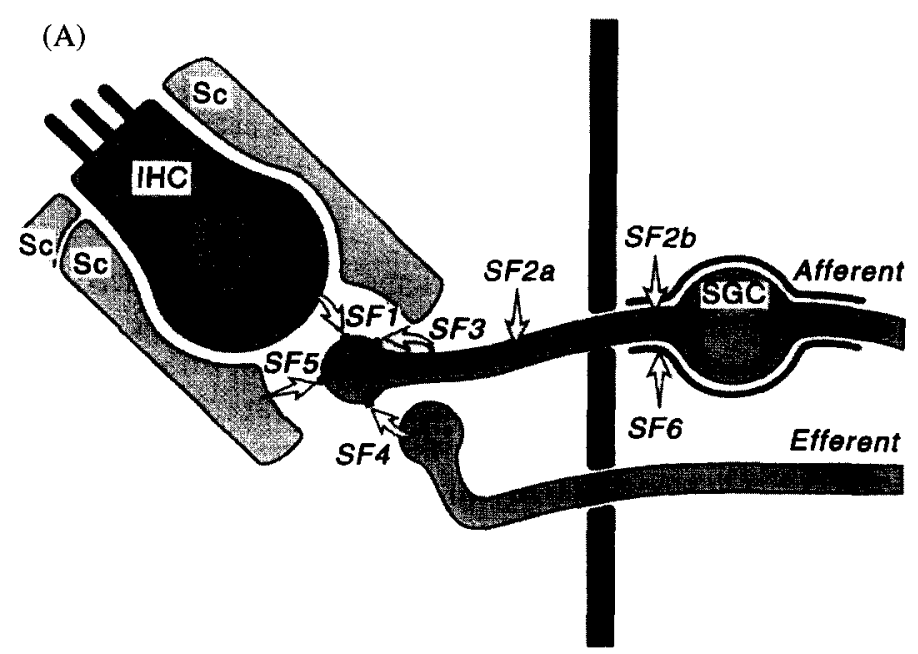

(B)

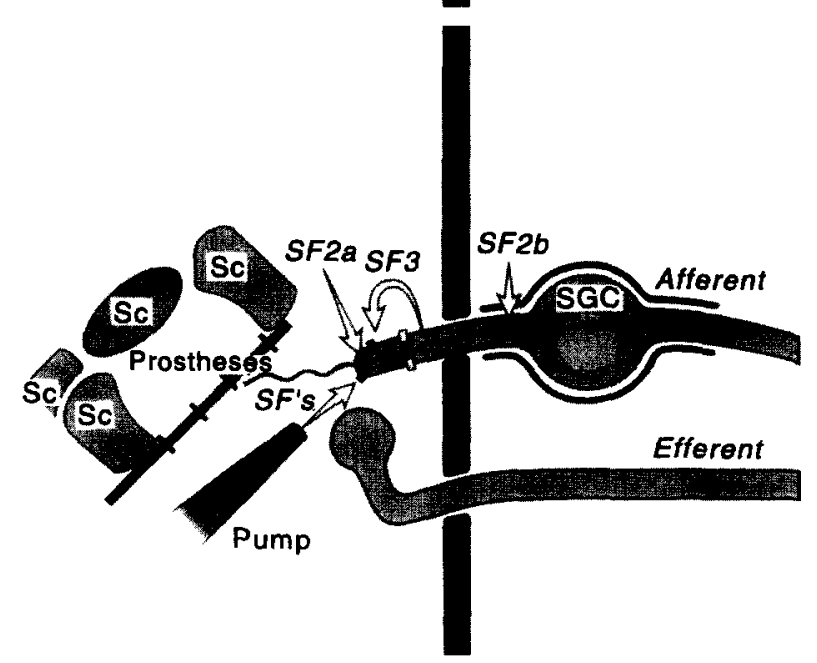

Fig. 6. (A) Model of the normal inner ear suggesting that various tissue elements may provide survival factors. SF1, from inner hair cells; SF2a, from generator potentials; SF2b, from action potentials; SF3, from fibers itself acting in an autocrine manner; SF4, from efferent fibers; SF5, from supporting cells; SF6, from Schwann cells. IHC is inner hair cell; Sc represents supporting cells. (B) Model of intervention and artificial addition of survival factors. Some absent factors may be introduced with chronic cannulation of the scala tympani and with cochlear prostheses to provide electrical stimulation. 
effect in the cochlea than BDNF. A significant effect for NT-3 has indeed been observed by a number of authors. ${ }^{8,43,45} \mathrm{We}$, on the other hand, saw a significant effect for BDNF and only a trend for NT-3. We speculate that the discrepancy between our data and other studies may reflect a number of experimental conditions. The concentrations we utilized were much lower ( 3 and $4 \mathrm{log}$ units) than those in other studies. Perhaps BDNF is more effective at lower concentrations while NT-3 is more effective at higher concentrations. We selected concentrations based on in vitro cell culture studies. Perhaps the $50 \mathrm{ng} / \mathrm{ml}$ used was not optimal, and perhaps the relative sensitivity and/or clearance of these factors differ in vivo in the cochlea. An effect for BDNF is not surprising since recent studies ${ }^{52}$ have shown that there is both BDNF and its receptor in the adult cochlea. Moreover, it is likely the distribution of receptor expression varies from developmental to mature, with the presence of pathology, and in the presence of exogenously administered neurotrophic factors.

Our finding that BDNF slows the rate of scar formation may also be pertinent. It may be that BDNF preserves supporting cells and stops them from entering a cell death cycle and turnover associated with scar formation after hair cell loss. Supporting cells may, in turn, be the source of an endogenous survival factor(s) important to SGC survival. Thus the result of BDNF enhancing SGC survival after deafness in the present study could be the combination of both direct effects on SGCs and indirect effects through an effect on supporting cells. Ernfors et al. ${ }^{8}$ described a similar effect on preserving supporting cells with NT-3. At the concentrations in our study, the effect on supporting cells (as with SGC preservation) was greater with BDNF than NT-3.

Survival factors interact and co-modulate one another's activity. ${ }^{18,32,56}$ Importantly, we know that activity induced by neurotrophic survival factors can be modulated by evoked activity. ${ }^{15}$ The experimental techniques and paradigm demonstrated in this study offer a special opportunity for new investigations of the inner ear and to engineer tissue survival in the face of peripheral hair cell loss. The techniques used here will, of course, be well supplemented by gene transfer technology, as described by Weiss et al..$^{50}$ The data reported here offer a first stage to maintaining neural elements with deafness and they may indeed, in the future, offer the opportunity for inducing the regrowth of peripheral processes perhaps up to and including the initiation of contact with implanted prostheses at selected sites adjacent to electrode locations. Such intimate and selective electrode tissue interface may afford an opportunity to take special advantage of new electrode technology and signal processing strategies to provide enhanced benefits to the deaf receiving cochlear implantation.

Acknowledgements-This work was supported in part by NIDCD program project DC00274, the Deafness Research Foundation's Medical Student Otological Fellowship, and the TWJ Fellowship Program. We would like to thank Diane Prieskorn, Peter Finger, Alice Mitchell and Dr Najaf Gholizadeh for their important contributions to these studies, and Annette Schmidt for expert secretarial assistance.

\section{REFERENCES}

1. Acheson A., Conver J. C., Fandl J. P., DeChiara T. M., Russell M., Thadani A., Squinto S. P., Yancopoulus G. D. and Linsay R. M. (1995) A BDNF autocrine loop in adult sensory neurons prevents cell death. Nature 374, 450-453.

2. Bohne B. A. (1976). Mechanisms of noise damage in the inner ear. In Effects of Noise on Hearing (eds Henderson D., Hamernik R. P., Dosanjh D. S. and Mills J. H.), pp. 41-68. Raven Press, New York.

3. Bohne B. A. and Harding G. W. (1992) Neural regeneration in the noise-damaged chinchilla cochlea. Laryngoscope 102, 693-703.

4. Brown J. N., Miller J. M., Altschuler R. A. and Nuttall A. L. (1993) Osmotic pump implants for chronic infusion of drugs into the inner ear. Hear. Res. 70, 167-172.

5. Bunge R. P. (1993) Expanding roles for the Schwann cell: ensheathment, myelination, trophism and regeneration. Curr. Opin. Neurobiol. 3, 805-809.

6. Coggleshall R. E. and Lekan H. E. (1996) Methods for determining numbers of cells and synapses: a case for more uniform standards of review. J. Comp. Neurol. 364, 6-15.

7. Engstrom H., Ades H. W. and Andersson A. (1966) Structural Pattern of the Organ of Corti: A Systematic Mapping of Sensory Cells and Neural Elements. Almqvist and Wiksell, Stockholm.

8. Ernfors P., Duan M. L., Elshamy W. M. and Canlon B. (1996) Protection of auditory neurons from aminoglycoside toxicity by neurotrophin-3. Nature Med. 2, 463-467.

9. Ernfors P., Lee K. F. and Jaenisch R. (1994) Mice lacking brain derived neurotrophic factor develop with sensory deficits. Nature 368, 147-150.

10. Ernfors P., Van De Water T., Loring J. and Yaenisch R. (1995) Complementary roles of BDNF and NT3 in vestibular and auditory development. Neuron 14, 1153-1164. 
11. Farinas I., Jones K. R., Backus C., Wang X. Y. and Reichardt L. F. (1994) Severe sensory and sympathetic deficits in mice lacking neurotrophin 3. Nature 369, 658-661.

12. Fritzsch B. (1996) The afferent innervation of the ear is supported by only two neurotrophins (BDNF, NT-3) and two neurotrophin tyrosine kinase receptors (TrkB, TrkC). Promega Neural Notes 1, 11-13.

13. Gantz B. J., Woodworth G. G., Abbas P. J., Knutsen J. F. and Tyler R. S. (1993) Multivariate predictors of audiological success with multichannel cochlear implants. Ann. Otol. Rhinol. Laryngol. 102, 909-916.

14. Gao W. Q. (1996) Neurotophin-4/5 promotes survival of spiral ganglion neurons and protects them from ototoxins in cochlear dissociated and organotypic cultures. 19th Midwinter Meeting, Association for Research in Otolaryngology, St. Petersburg, FL, 4-8 February. Abstract, p. 11.

15. Green S. H., Hegarty J. L and Kay A. R. (1995) Factors promoting survival of spiral ganglion neurons. The Molecular Biology of Hearing and Deafness, Bethesda, MD, 6-8 October. Abstract, p. 39.

16. Hartshorn D. O., Miller J. M. and Altschuler R. A. (1991) Protective effect of electrical stimulation on the deafened guinea pig cochlea. Otolaryngol. Head Neck Surg. 104, 311-319.

17. Jyung R. W., Miller J. M. and Cannon S. C. (1989) Evaluation of eighth nerve integrity using electrically evoked middle latency response. Am. Acad. Otolaryngol. 101, 670-682.

18. Kato A. C. and Lindsay R. M. (1994) Overlapping and additive effects of neurotrophins and CNTF on cultured human spinal cord neurons. Exp. Neurol. 130, 196-201.

19. Kileny P. R. and Zimmerman-Phillips S. (1988) Effects of auditory deprivation on performance with multichannel implant. $A S H A$ 10, 30.

20. Kopke R., Staecker H., Garcia P., Feghali J., Lefebvre P. P. and Van De Water T. R. (1996) Rescue of auditory neurons through scala tympani infusion of either NT-3 or BDNF after ototoxin/ethacrynic acid destruction of hair cells in the guinea pig. 19th Midwinter Meeting, Association for Research in Otolaryngology, St. Petersburg, FL, 4-8 February. Abstract, p. 200.

21. Kruszka P., Miller J. M. and Raphael Y. (1996) The effect of in vivo administration of growth factors to spiral ganglion of the cochlea. 19th Midwinter Meeting, Association for Research in Otolaryngology, St. Petersburg, FL, 4-8 February. Abstract, p. 144.

22. Lawner B. E., Harding G. W. and Bohne B. A. (1997) Time course of nerve-fibre regeneration in the noise-damaged mammalian cochlea. Int. J. Dev. Neurosci. 15, 601-617.

23. Leake P. A., Hradek G. T., Rebscher S. J. and Snyder R. L. (1991) Chronic intracochlear electrical stimulation induces selective survival of spiral ganglion neurons in neonatally deafened cats. Hear. Res. 54, 251-271.

24. Leake P. A., Snyder R. L., Hradek G. T. and Rebscher S. J. (1992) Chronic intracochlear stimulation in neonatally deafened cats: effects of intensity and stimulating electrode position. Hear. Res. 64, 99-117.

25. Leake P. A., Snyder R. L., Hradek G. T. and Rebscher S. J. (1995) Consequences of chronic electrical stimulation in neonatally deafened cats. Hear. Res. 82, 65-80.

26. Lefebvre P. P., Malgrange B., Staecker H., Moghadass M., Van De Water T. R. and Moonen G. (1994) Neurotrophins affect survival and neuritogenesis by adult injured auditory neurons in vitro. NeuroReport 5, 865-868.

27. Lefebvre P. P., Van De Water T. R., Staecker H., Weber T., Galinovic-Schwartz V., Moonen G. and Ruben R. J. (1992) Nerve growth factor stimulates neurite regeneration but not survival of adult auditory neurons in vitro. Acta Otolaryngol. 112, 293-299.

28. Lousteau R. J. (1987) Increased spiral ganglion cell survival in electrically stimulated, deafened guinea pig cochleae. Laryngoscope $97,837-842$.

29. Malgrange B., Lefebvre P. P., Van De Water T. R., Staecker H., Rogister B. and Moonen G. (1995) Neurotrophins effects on developing rat auditory neurons in culture. The Molecular Biology of Hearing and Deafness, Bethesda, MD, 6-8 October. Abstract, p. 38.

30. Miller J. M. and Altschuler R. A. (1995) Effectiveness of different electrical stimulation conditions in preservation of spiral ganglion cells following deafness. Ann. Otol. Rhinol. Laryngol. 166, 57-60.

31. Miller J. M., Prieskorn D. M., Gholizadeh N., Finger P. A. and Altschuler R. A. (1996) Blocking auditory nerve action potential for three to six weeks with chronic infusion of TTX does not induce spiral ganglion cell death. 19th Midwinter Meeting, Association for Research in Otolaryngology, St. Petersburg, FL, 4-8 February, Abstract, p. 106.

32. Mou K. and Davis R. L. (1996) Synergistic effects of neurotrophins on primary-auditory neurons in vitro. 19th Midwinter Meeting, Association for Research in Otolaryngology, St. Petersburg, FL, 4-8 February. Abstract, p. 11.

33. Pfingst B. E., Glass I., Spelman F. A. and Sutton D. (1985) Psychophysical studies of cochlear implants in monkeys: clinical implications. In Cochlear Implants (eds Schindler R. A. and Merzenich M. M.), pp. 305-321. Raven Press, New York.

34. Pfingst B. E., Sutton D., Miller J. M. and Bohne B. A. (1981) Relation of psychophysical data to histopathology in monkeys with cochlear implants. Acta Otolaryngol. 92, 1-13.

35. Pirvola U., Arumae U., Moshnyakov M., Palgi J., Saarma M. and Ylikoski J. (1994) Coordinated expression and function of neurotrophins and their receptors in the rat inner ear during target innervation. Hear. Res. 75, 131-144.

36. Pirvola U., Ylikoski J., Palgi J., Lehtonen E., Armae U. and Saarma M. (1992) Brain-derived neurotrophic factor and neurotrophin 3 mRNAs in the peripheral target fields of developing inner ear ganglia. Proc. Natl Acad. Sci. USA 89, 9915-9919.

37. Raphael Y. and Altschuler R. A. (1991) Scar formation after drug-induced cochlear insult. Hear. Res. 51, 173-184.

38. Schecterson L. C. and Bothwell M. (1994) Neurotrophin and neurotrophin receptor mRNA expression in developing inner ear. Hear. Res. 73, 92-100.

39. Schindler R. A., Gladstone H. B., Scott N., Hradek G. T., Williams H. and Shah S. B. (1995) Enhanced preservation of the auditory nerve following cochlear perfusion with nerve growth factor. Am. J. Otol. 16, 304-309.

40. Seidman M. D., Quirk W. S., Nuttall A. L. and Schweitzer V. G. (1991) The protective effects of allopurinol and superoxide dismutase-polyethylene glycol on ischemic and reperfusion-induced cochlear damage. Otolaryngol. Head Neck Surg. 105, 457-463.

41. Shah S. B., Gladstone H. B., Williams H., Hradek G. T. and Schindler R. (1995) An extended study: protective effects of nerve growth factor in neomycin induced auditory neural degeneration. Am. J. Otol. 16, 310-316.

42. Spoendlin H. (1984) Factors inducing retrograde degeneration of the cochlear nerve. Ann. Otol. Rhinol. Laryngol. 93(suppl.), 76-81. 
43. Staecker H., Kopke R., Malgrange B., Lefebvre P. and Van de Water T. R. (1996) NT-3 and/or BDNF therapy prevents loss of auditory neurons following loss of hair cells. Neuro Report 7, 889-894.

44. Van De Water T. R., Frenz D. A., Giraldez F., Represa J., Lefebvre P. P., Rogister B. and Moonen G. (1992) Growth factors and development of the statoacoustic system. In Development of Auditory and Vestibular Systems, (ed. Romand), pp. 1-32. Elsevier, Amsterdam.

45. Van De Water T. R., Staecker H., Kopke R., Liu W., Hartnick C., Malgrange B., Lefebvre P. P. and Moonen G. (1995) Neurotrophic factors: maintenance and injury-repair of auditory neurons. The Molecular Biology of Hearing and Deafness, Bethesda, MD, 6-8 October, Abstract, p. 7.

46. Vasquez E., Van De Water T. R., Del Valle M., Vega J. A., Staecker H., Giraldez F. and Represa J. (1994) Pattern of trkB protein-like immunoreactivity in vivo and the in vitro effects of brain-derived neurotrophic factor (BDNF) on developing cochlear and vestibular neurons. Anatomy Embryol. 189, 157-167.

47. Wangemann A. P. and Schacht J. (1996) Homeostatic mechanisms in the cochlea. In Handbook of Auditory Research (eds Fay R. R. and Popper), Vol IX: The Cochlea (ed. Dallos P.), pp. 130-185. Springer, New York.

48. Webster D. B. (1996) Long term sequelae of organ of Corti loss in guinea pigs. 19 th Midwinter Meeting, Association for Research in Otolaryngology, St. Petersburg, FL, 4-8 February Abstract, p. 205.

49. Webster M. and Webster D. B. (1981) Spiral ganglion neuron loss following organ of Corti loss: a quantitative study. Brain Res. 212, 17-30.

50. Weiss M. A., Frisancho J. C., Roessler B. J. and Raphael Y. (1997) Viral mediated gene transfer in the cochlea. Int. J. Dev. Neurosci. 15, 577-583.

51. West B. A., Brummett R. E. and Himes D. C. (1973) Interaction of kanamycin and ethacrynic acid: severe cochlear damage in guinea pigs. Arch. Otolaryngol. 98, 17-30.

52. Wheeler E. F., Bothwell M., Schecterson L. C. and von Bartheld C. S. (1994) Expression of BDNF and NT-3 mRNA in hair cells of the organ of Corti: quantitative analysis in developing rats. Hear. Res. 73, 46-56.

53. Ylikoski J., Pirvola U., Moshnyakov M., Palgi J., Arumae U. and Saarma M. (1993) Expression patterns of neurotrophin and their receptor mRNAs in the rat inner ear. Hear. Res. 65, 69-78.

54. Zappia J. J. and Altschuler R. A. (1989) Evaluation of the effect of ototopical neomycin on spiral ganglion cell density in the guinea pig. Hear. Res. 40, 29-38.

55. Zheng J. L., Stewart R. R. and Gao W. Q. (1995) Neurotrophin-4/5 enhances survival of cultured spiral ganglion neurons and protects them from cisplatin neurotoxicity. $J$. Neurosci. 15, 5079-5087.

56. Zhong W., Zaheer A. and Lira R. (1994) Ciliary neurotrophic factor enhances the effects of nerve growth factor on PC12 cells. Brain Res. 661, 56-62. 